\title{
Optimization of growth conditions For zinc Solubilizing Plant Growth associated Bacteria and Fungi
}

\author{
Shabnam S Shaikh and Meenu S Saraf* \\ Department of Microbiology and Biotechnology, School of sciences, Gujarat University, Ahmedabad
}

Received: 02 February, 2017; Accepted: 03 March, 2017; Published: 17 March, 2017

*Corresponding author: Meenu S Saraf, Department of Microbiology and Biotechnology, School of sciences, Gujarat University, Ahmedabad, Tel: +91-7926303225; Fax: +91-79-26851704; E-mail: sarafmeenu@gmail.com

\begin{abstract}
Zinc (Zn) is an essential element necessary for plant, humans and microorganisms required in little quantities to compose a complete array of physiological functions. Rhizospheric microbes are known to influence plant growth by various direct and indirect mechanisms and have some additional properties such as multiple metal solubilization. In the current investigation, we have isolated zinc solubilizing microbes and optimized their growth condition for further application in agriculture industry. Seven isolates amongst which four fungi and three fungi were studied for their Plant growth promoting ability, Zinc solubilization and optimization of growth Isolate MSSZB4 and MSS-ZF3 were showing significant Plant promoting abilities and shows best optimization with $0.1 \% \mathrm{ZnO}$ concentration, dextrose as carbon source, Ammonium Sulphate as nitrogen source and the optimum $\mathrm{pH}$ and Temperature was found between 6 to 6.5 and 28 to $30^{\circ} \mathrm{C}$ respectively. The present study demonstrates the optimum growth conditions for zinc solubilizing microbes, which can further be used for their potential applications, such as biofortification and bioremediations.
\end{abstract}

Keywords: Zinc; Solubilization; Plant growth promoting properties; Optimization

\section{Introduction}

Plant growth promoting rhizobacteria can affect plant growth by different direct and indirect mechanisms [1]. PGPR influence direct growth promotion of plants by fixing atmospheric nitrogen, solubilizing insoluble phosphates, secreting hormones such as IAA, GAs, and Kinetics besides ACC deaminase production, which helps in regulation of ethylene. Induced systemic resistance (ISR), antibiosis, competition for nutrients, parasitism, production of metabolites (hydrogen cyanide, siderophores) suppressive to deleterious rhizobacteria are some of the mechanism that indirectly benefit plant growth. Zinc (Zn) is an essential element necessary for plant, humans and microorganisms [2,3]. Human and other living things require $\mathrm{Zn}$ throughout requires in little quantities to compose a complete array of physiological functions. Zinc is a vital mineral of "exceptional biological and public health importance" [4]. Furthermore 100 specific enzymes are found in which zinc serves as structural ions in transcription factors and is stored and transferred in metallothioneinsand typically the $2^{\text {nd }}$ most abundant transition metal in organisms, after iron and it is the only metal which appears in all enzyme classes [3].

Zinc is important micronutrient for plant which plays numerous functions in life cycle of plants [5]. Crop growth, vigor, maturity and yield are very much reliant upon essential micronutrient $(\mathrm{Zn})$. To address the problem of $\mathrm{Zn}$ deficiency, micronutrient biofortification of grain crop is increased interest in developing countries [6]. Several approaches have been projected and practiced for fortification of cereals [7]. Enhancing $\mathrm{Zn}$ concentration of cereal grain has been recognized as an approach of tackling human Zn deficiency [8]. Plant scientists are formulating different methodologies to tackle the $\mathrm{Zn}$ deficiencies in crop through fertilizes applications and/ or by means of plant breeding strategies to augment the adsorption and or bioavailability of $\mathrm{Zn}$ in grain crops [6].

Plant growth promoting rhizobacteria (PGPR) is multifunction microbes functioning in sustainable agriculture. PGPR are a diverse group of bacteria that can be found in the rhizosphere on root surfaces as well as in association with roots [9]. These bacteria move around from the bulk soil to the living plant rhizosphere and antagonistically colonize the rhizosphere and roots of plant [10]. Soil bacteria which are important for plant growth are termed as plant growth promoting rhizobacteria (PGPR) [10]. In addition to phosphate mobilization they are responsible to play key role in carrying out the bioavailability of soil phosphorus, potassium, iron, zinc and silicate to plant roots [11].

Viable application of PGPR are been tested and are repeatedly promising; however, good understanding of microbial interactions will significantly raise the success rate of field application [12].

\section{Material and Methods}

\section{Physical and chemical characterization of soil sample}

Three soil samples were collected from rhizosphere region of Agriculturall and were collected from the different region of Gujarat. Physical characteristics, various chemical tests likes alinity, $\mathrm{pH}$, total carbon, phosphates, total dissolved solids, edoxpotential (mV), conductivity, chlorides, Sulphate, potassium, 
nitrates as well as micro metals present in the soil like Few were also characterize for soil samples.

\section{Qualitative and quantitative phosphate solubilization}

Phosphate Solubilization was studied using tricalcium phosphateas in soluble phosphate. The strains were spotinoculated on Pikovskaya's agar medium. The plates were incubated with $30{ }^{\circ} \mathrm{C}$ for 48 to $72 \mathrm{~h}$ for bacteria and 3 to 6 days for fungi. The clear halo around the colony indicates the zone of phosphate Solubilization due to the production of organic acids as possible mechanism of the phosphate solubilization. Quantitative phosphate Solubilization was carried out in liquid Pikovskaya's medium in $250 \mathrm{ml}$ flasks for $14 \mathrm{~d}$.

The concentration of the soluble phosphate in the supernatant was estimated every 7dayby Stannous Chloride ( $\mathrm{SnCl} 2.2 \mathrm{HO}$ ) method [13]. A simultaneous change in the $\mathrm{pH}$ was also recorded in the supernatant on Systronics digital $\mathrm{pH}$ meter $\mathrm{pH}$ system 361).

\section{Qualitative and quantitative production of Siderophore}

Siderophore production was checked by using Chrome azurols (CAS) agar medium by the method described by Schwyn and Neilands, [14]. Actively growing cultures were spot inoculated on the CAS blue agar plate. These plates were then incubated at 37 ${ }^{\circ} \mathrm{C}$ for 48 to $72 \mathrm{~h}$ for Bacteria and at $28{ }^{\circ} \mathrm{C}$ for 3-6 days for fungi. Formation of yellow-orange halo around the colony indicated production and release of the siderophores on the agar plate.

\section{Indole Acetic Acid production}

Auxin production was studied in trypton yeast medium Bacteria were grown in $50 \mathrm{ml}$ yeast extract broth supplemented with $50 \mathrm{mgL}^{-1}$ of L-Tryptophan and incubated in dark on orbital shaker at $200 \mathrm{rpm}$ for $72 \mathrm{~h}$. Hormone production was checked in supernatant using Salkowsky's reagent method [15]. The amount of IAA produced was calculated from the standard graph of pure indole acetic acid. Study was carried out every $24 \mathrm{~h}$ for up to 120 $\mathrm{h}$ and the pattern of IAA production was recorded.

\section{Ammonia and HCN production}

Each strain was tested for the production of ammonia in peptone water. Cultures $(100 \mu \mathrm{l}$ inoculum with approximately 3 x $10^{8}$ c.f.u. $\mathrm{ml} \mathrm{-1)} \mathrm{were} \mathrm{inoculated} \mathrm{in} 10 \mathrm{ml}$ peptone water and these plates were then incubated at

$37{ }^{\circ} \mathrm{C}$ for 48 to $72 \mathrm{~h}$ for Bacteria and at $28^{\circ} \mathrm{C}$ for 3-6 days for fungi. After Incubation Nessler's reagent ( $1 \mathrm{ml}$ ) was added to each tube. Development of brown to yellow colour was recorded as a positive test for ammonia production [16]. Production of hydrocyanic acid (HCN) was checked on nutrient agar slants streaked with the test isolates. Filter paper strips dipped in picric acid and $2 \%$ sodium carbonate were inserted in the tubes. HCN production was checked based on changes in colour from yellow to light brown, moderate brown or strong brown of the yellow filter paper strips [17].

\section{Exopolysaccharide (EPS) production}

Normally EPS production is studied in basal medium of all different organisms. Ascarbohydrate source $5 \%$ of sucrose is to be added as polysaccharide in to the medium [18]. $10 \mathrm{ml}$ of culture suspension was collected after 5-6 days and centrifuge at 30,000 rpm for 45 minutes add thrice the volume of chilled acetone. EPS will be separated from the mixture in the form of a slimy precipitates.

\section{Zinc solubilization}

The BTG medium was mixed with thorough stirring to obtain a homogeneous suspension. Experiments in liquid culture were performed in a defined Mineral Salt Medium (MSM), with glucose (10 g) as the sole carbon source and, when required, $0.1 \%$ insoluble zincoxide [19]. The dilution medium for viable counts was sterile $\mathrm{NaCl}$ solution, $8 \mathrm{~g}$ /liter. All glass ware used was soaked for $1 \mathrm{~h}$ in $1 \mathrm{M} \mathrm{HCl}$ and rinsed three times in distilled deionized water prior to use. Inoculation was carried out by using pure colony of a bacteria and fungi. It was inoculated to medium and allowed to grow. (For Bacteria at $37^{\circ} \mathrm{C}$ and for fungi at 28 C) for 14 days respectively [20]. The Zone of Solublization was Observed and measured in millimeter $(\mathrm{mm})$.

\section{Zinc solubilization in PVK (Pikovskaya's medium)}

Zinc solubilization was checked using zinc oxide as insoluble zinc source. Spot inoculation of the isolates was done in the centre of the Pikovskaya's agar medium. These plates were then incubated at $37^{\circ} \mathrm{C}$ for 48 to $72 \mathrm{~h}$ for Bacteria and at $28 \mathrm{oC}$ for 3-6 days for fungi. Phosphate solubilization was checked in the form of a clear halo formed around the colony representing the production of organic acids as a possible mechanism of the zinc solubilization. Quantitative zinc solubilization was carried out in liquid Pikovskaya's medium in $250 \mathrm{ml}$ flasks for $14 \mathrm{~d}$ [21].

Optimization of Media and Growth Condition for Zinc Solubilization: Zinc solubilizing ability of bacterial strains was tested in four different types of agar media. Composition of different media is given in table. Among them PVK (Pikovskaya'smedium) media with $0.1 \%$ Zinc Oxide was selected based on proper zone formation, opacity of medium and growth of isolates [21].

Effect of various Zinc source on efficiency of Zinc Solubilization: Effect of various Zinc sources like Zinc Carbonate, ZincSulphate and Zinc Oxide, were studied in PVK Broth. The isolates were checked for solubilization activity in PVK broth amended with different Zinc source. Inoculation was carried out by using pure colony of a bacteria and fungi. It was inoculated to medium and allowed to grow. (for Bacteria at $37 \mathrm{oC}$ and for fungi at $28^{\circ} \mathrm{C}$ ) for 14 days respectively [20]. The Zone of Solubilization was observed and measured in millimetre $(\mathrm{mm})$. Zinc oxide was selected as the optimum zinc source for the further optimization, based on proper zone formation and opacity of the medium.

Effect of different concentration of Zinc Oxide on efficiency of Zinc Solubilization: Effect of different concentration of Zinc Oxide was added in the PVK agar medium which was $0.1 \%, 0.2 \%$, 
$0.3 \%, 0.4 \%$ and $0.5 \%$. Nitrogen sources like (NH4)2SO4, Urea, Casein, and NaNO3 were studied in PVK Broth. Inoculation was carried out by using pure colony of a bacteria and fungi. It was inoculated to medium and allowed to grow. (for Bacteria at $37^{\circ} \mathrm{C}$ and for fungi at $28^{\circ} \mathrm{C}$ ) for 14 days respectively [20]. The zone of solubilization was Observed and measured in millimetre ( $\mathrm{mm}$ ).

Effect of various Carbon sources on efficiency of Zinc solubilization: Effect of various carbon sources like glucose, fructose, sucrose, lactose, glycerol and xylose, were studied in PVK agar plate. The isolates were checked for solubilization activity in PVK agar medium amended with $0.1 \%$ Zinc Oxide. Inoculation was carried out by using pure colony of a bacteria and fungi. It was inoculated to medium and allowed to grow. (For Bacteria at $37^{\circ} \mathrm{C}$ and for fungi at $28^{\circ} \mathrm{C}$ ) for 14 days respectively [20]. The Zone of Solubilization was Observed and measured in millimetre (mm).

Effect of various Nitrogen sources on efficiency of Zinc solubilization: Effect of various Nitrogen sources like (NH4)2SO4, Urea, Casein, and NaNO3 were studied in PVK Broth. The isolates were checked for solubilization activity in PVK broth amended with $0.1 \%$ Zinc Oxide. Inoculation was carried out by using pure colony of a bacteria and fungi. It was inoculated to medium and allowed to grow. (For Bacteria at $37^{\circ} \mathrm{C}$ and for fungi at $28^{\circ} \mathrm{C}$ ) for 14 days respectively [20]. The zone of solubilization was Observed and measured in millimetre ( $\mathrm{mm})$.

Effect of temperature on efficiency of Zinc solubilization: Media composition to which the bacteria responded best was used as substrate. Inoculation was carried out by using pure colony of a bacterial grown on Basal medium of isolates and allowed to grow and maintained at $8^{\circ} \mathrm{C}, 15^{\circ} \mathrm{C}, 28^{\circ} \mathrm{C}$, Room Temperature, $37^{\circ} \mathrm{C}$, and $55^{\circ} \mathrm{C}$ for 14 days respectively [20]. The zone of solubilization was observed and measured in millimetre $(\mathrm{mm})$.

Effect of pH on efficiency of Zinc Solubilization: Optimal media and temperature was used, but the $\mathrm{pH}$ of the media was set at $\mathrm{pH} 4, \mathrm{pH} 6, \mathrm{pH} 6.5, \mathrm{pH} 7, \mathrm{pH} 9$ using $\mathrm{NaOH}$ or $\mathrm{HCl}$ and grown for 14 days respectively [20].The Zone of solubilization was Observed and measured in millimetre ( $\mathrm{mm})$.

Effect of different Salinity on efficiency of Zinc Solubilization: Optimal media and Conditions were used, but the saline concentration was added as $\mathrm{NaCl}(0.2 \%, 0.4 \%, 0.6 \%$, $0.8 \%$ and $1 \%)$ and $\mathrm{KCl}(0.02 \%, 0.04 \%, 0.06 \%, 0.08 \%$ and $0.1 \%)$ in the media was set and grown for 14 days respectively [20]. The zone of solubilization was Observed and measured in millimetre $(\mathrm{mm})$.

\section{Results and Discussion}

\section{Physical characterization of soil samples}

Physical characteristics of all the different soil samples shows that soil from rhizosphere was brown in colour and its texture was granular to loamy. The chemical characterization of soil samples is shown in (Table 1). The observed variation in the $\mathrm{pH}$ could be due to heterogenous composition of soil at all the three sites. Similar results were also reported by Amanul where variations were observed in soil samples of different agricultural soils [22]. Higher Organic and nitrogen content.

\section{Isolation and Microbiological characterization of the soil samples}

Total 20 isolates from three soil samples were screened for phosphate, zinc solubilization and giving maximum growth (fast grower). Among them Seven isolates were selected (four bacteria and three fungi) for further studies. They were purified on their respective medium.

\section{Qualitative and quantitative phosphate solubilization}

Phosphate solubilization results show that all the seven isolates were significant Phosphate solubilizers and showing zone of phosphate solubilization on solid Pikovskyaya's medium after 3 days of incubation at $30 \pm 2^{\circ}$ C. Maximum zone was observed in isolate MSS-ZF3 (49 mm). Significant zones were also seen in MSS-ZF2 (45mm), MSS-ZB4(43 mm), MSS-ZF1 (40 $\mathrm{mm})$, MSS-ZB2(35 mm) MSS-ZB1 (33 mm)and MSS-ZB3(30 mm) after eight days of incubation (Figure 1).

Maximum TCP (Tricalcium phosphate) solubilization in liquid medium was observed in MSS-ZF3 $(29 \mu \mathrm{g} / \mathrm{ml})$ followed by MSS-ZF2 ((24 $\mu \mathrm{g} / \mathrm{ml})$, MSS-ZB4 (37 $\mu \mathrm{g} / \mathrm{ml})$, MSS-ZF1 (18 $\mu \mathrm{g} /$

Table 1: Chemical characteristics of soil samples.

\begin{tabular}{|c|c|c|c|}
\hline Parameters & Sample 1 & Sample 2 & Sample 3 \\
\hline pH & 8.25 & 8.36 & 7.89 \\
\hline Organic carbon (\%) & 1.26 & 0.17 & 0.15 \\
\hline Available Nitrogen (\%) & 0.10 & 0.13 & 1.77 \\
\hline $\mathbf{P}_{\mathbf{2}} \mathbf{O}_{\mathbf{5}}$ (ppm) & 1.211 & 1.197 & 1.156 \\
\hline $\mathbf{K}_{\mathbf{2}} \mathbf{O}(\mathbf{p p m})$ & 19 & 14 & 16 \\
\hline Available Fe (ppm) & 4.3 & 4.06 & 5.09 \\
\hline Available K (kg/hec) & 538 & 202 & 409 \\
\hline Available Zn (ppm) & 3.62 & 3.70 & 4.20 \\
\hline Available cu (ppm) & 1.00 & 1.14 & 1.19 \\
\hline Available Mn (ppm) & 3.62 & 3.70 & 4.02 \\
\hline HCN Production by the Isolates & & \\
\hline
\end{tabular}

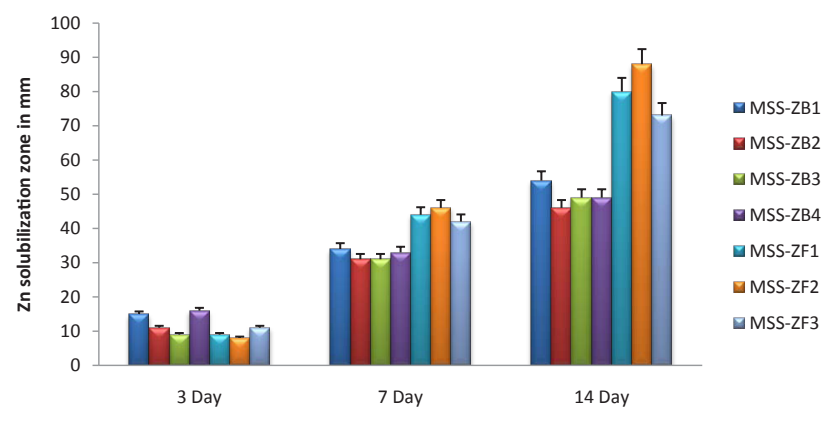

Figure1: Zinc solubilization by the selected isolates. 
$\mathrm{ml})$ and MSS-ZB2 $(16 \mu \mathrm{g} / \mathrm{ml}), \operatorname{MSS}-Z B 1(12 \mu \mathrm{g} / \mathrm{ml})$ and MSS ZB3 $(10 \mu \mathrm{g} / \mathrm{ml})$ in 3.2). The result observed was that the isolates showed maximum zone of solubilization on solid medium, are also showing similar phosphate solubilization in liquid medium. The $\mathrm{pH}$ of the broth having fungal isolates has been decreased from 7.0 to 4.0. The observed result shows that in bacterial culture there was no decrease in $\mathrm{pH}$, but in all the fungal isolates it shows the decrease in broth $\mathrm{pH}$. The results showing no correlation between Phosphate solubilization and $\mathrm{pH}$ reduction are also published by many researchers (Tank and Saraf 2003). This drop-in pH may also be an attribute of glucose utilization by the isolates (Arora et al. 2008). Plant growth is frequently limited by an insufficiency of phosphates, an important nutrient in plants next to nitrogen. Although all isolates showed similar decline in $\mathrm{pH}, 3.3$ - 4.5, amount of phosphate solubilization was different in different PGPR's isolated. This indicates that there is no relation between degree of phosphate solubilized and change in $\mathrm{pH}$ [13].

\section{Qualitative and quantitative siderophore production}

The universal assay described by Schwyn and Neilands was used for the detection of siderophore by different microorganisms (fungi and bacteria) in solid medium. Siderophore on solid CAS blue agar plate shows a clear zone of decolourization representing iron chelation by the isolate in the medium. Highest zone of dye decolourization was observed in MSS-ZF3 (20 mm), MSS-F2 (18 $\mathrm{mm})$, MSS-ZF1 (16 mm), MSS-ZB1(14 mm) and MSS-ZB3(10 mm) after $120 \mathrm{~h}$ of Incubation. And no zone was observed in MSSZB2.Siderophore was detected by the formation of orange halos surrounding bacterial colonies on CAS agar plates after 48 hour at $28^{\circ} \mathrm{C}[23]$.

\section{Indole Acetic Acid Production}

All the seven selected isolates showed significant production of IAA. Highest IAA production was reported in MSS-ZF1 (44 $\mu \mathrm{g} /$ $\mathrm{ml})$, MSS-ZF2 (40 $\mu \mathrm{g} / \mathrm{ml})$, MSS-ZB1 $(24 \mu \mathrm{g} / \mathrm{ml})$, MSS-ZB2 $(19 \mu \mathrm{g} /$ $\mathrm{ml})$, MSS-ZF3 $(18 \mu \mathrm{g} / \mathrm{ml})$ and MSS-ZB4 $(14 \mu \mathrm{g} / \mathrm{ml})$. All the isolates showed a continuous increase in the IAA production within the incubation period of 6 days.

Different isolates showed different optimum incubation time for highest IAA production. It is estimated that about $80 \%$ of soil bacteria possess IAA producing potential [24].Though reports reveal that IAA production reaches maximum after $120 \mathrm{~h}(5 \mathrm{~d})$ of incubation many of our isolates did not follow this pattern and showed maximum IAA production even after $240 \mathrm{~h}(10 \mathrm{~d})$ [25]. However, reports of other researchers showed that IAA production was not detected after $5 \mathrm{~d}$. Though it is reported that there is continuous decrease in IAA production after reaching the peak production, this pattern was also followed by our isolates. IAA production curves of the isolates showed continuous increase and decrease up to $12 \mathrm{~d}$. These types of curves are in agreement with the IAA production curves reported by TorresRubioet al $[26,27]$. The reason for such fluctuations could be the utilization of IAA by the cells as nutrient during late stationary phase or production of IAA degrading enzymes by the cells which are inducible enzymes in presence of IAA [26].

\section{Ammonia and HCN production}

Ammonia production was studied up to $42-72 \mathrm{~h}$ of incubation as per method given. Maximum concentration of ammonia production was observed in isolates MSS-ZB4 $(32 \mu \mathrm{g} / \mathrm{ml})$ followed by MSS-ZB3 $(29 \mu \mathrm{g} / \mathrm{ml})$, MSS-ZB1 $(27 \mu \mathrm{g} / \mathrm{ml})$, MSS-ZF3 $(24 \mu \mathrm{g} / \mathrm{ml}), \mathrm{MSS}-\mathrm{ZF} 2(22 \mu \mathrm{g} / \mathrm{ml}), \mathrm{MSS}-\mathrm{ZSF} 1(21 \mu \mathrm{g} / \mathrm{ml})$ and MSSZB2 $(19 \mu \mathrm{g} / \mathrm{ml})$.

Ammonia released by diazotrophs is one of the mostimportant traits of PGPR's which benefits the crop [25]. This accumulation of ammonia in soil may increase in $\mathrm{pH}$ creating alkaline condition of soil at $\mathrm{pH}$ 9-9.5. It suppresses the growth of certain fungi and nitrobacteria due to it potent inhibition effect. Christiansen et al. have reported that level of oxygen in aerobic conditions was same as the level of ammonia excretion under oxygen limiting conditions. However, Joseph et al. reported ammonia production in 95\% of isolates of Bacillus followed by Pseudomonas (94.2\%), Rhizobium (74.2\%) and Azotobacter (45\%) [3,4,7,29-32].

HCN production was checked in all isolates the results are showed in table 6. Presence or absence and intensity of HCN production can play a significant role in antagonistic potential of bacteria against phytopathogens. Similar results were also reported by Cattelan et al. who reported that production of cyanide was an important trait in a PGPT in controlling fungal diseases in wheat seedlings under in-vitro conditions. Chandra et al. reported production of HCN by the PGPR which was inhibitory to the growth of $S$. sclerotium. Kumar et al. also reported in vitro antagonism by HCN producing PGPR against sclerotia germination of M. phaseolina. Production of HCN along with siderophore production has been reported as the major cause of biocontrol activity for protection of Black pepper and ginger [30,33-35].

Table 2: HCN production by the Isolates.(+ positive) and (- negative).

\begin{tabular}{|c|c|}
\hline Isolates & Result \\
\hline MSS-ZB1 & + \\
\hline MSS-ZB2 & - \\
\hline MSS-ZB3 & +++ \\
\hline MSS-ZB4 & ++ \\
\hline MSS-ZF1 & - \\
\hline MSS-ZF2 & - \\
\hline MSS-ZF3 & - \\
\hline
\end{tabular}

Table 3: $\mathrm{pH}$ change in the liquid medium.

\begin{tabular}{|c|c|c|c|}
\hline Isolate & $\mathbf{2}^{\text {nd }} \mathbf{d a y} \mathbf{~} \mathbf{H}$ & $\mathbf{4}^{\text {th }} \mathbf{d a y} \mathbf{~ p H}$ & $\mathbf{6}^{\text {th }} \mathbf{d a y} \mathbf{~} \mathbf{H}$ \\
\hline MSS-ZB1 & 7.0 & 6.0 & 5.4 \\
\hline MSS-ZB2 & 6.9 & 6.1 & 5.1 \\
\hline MSS-ZB3 & 6.8 & 6.2 & 5.2 \\
\hline MSS-ZB4 & 7.0 & 6.3 & 5.3 \\
\hline MSS-ZF1 & 6.5 & 6.0 & 5.0 \\
\hline MSS-ZF2 & 6.5 & 5.9 & 4.9 \\
\hline MSS-ZF3 & 6.5 & 5.8 & 4.8 \\
\hline
\end{tabular}




\section{Exopolysaccharide (EPS) production by selected isolates}

From all the Seven culture, the three bacterial isolates shows EPS Production, maximum amount of EPS production was observed in isolate MSS-ZB1(44.5 mg/ ml) followed by MSSZB3 (30.5 mg/ ml) and MSS-ZB4 $(20.0 \mathrm{mg} / \mathrm{ml})$ after five days of incubation.

Maximum of EPS production occurs during early stationary phase than in the late stationary of culture [18]. The highest EPS production was recorded in $P$. aeruginosa $(226 \mu \mathrm{g} / \mathrm{ml})$ grown in nitrogen free medium followed by $S$. mutansand B. subtilis $(220$ and $206 \mu \mathrm{g} / \mathrm{ml}$ respectively) in nitrogen free medium after 7 days of incubation at $37^{\circ} \mathrm{C}$ reported that production of EPS by Burkholderia gladioli IN-26 a strain of PGPR reduced bacterial speck on tomato. Similarly, Alami etal. reported that EPS produced by root associated saprophytic bacterium (rhizobacterium) PantoeaagglomeransYAS34 was associated with plant growth promotion of sunflower reported that Paenibacillus polymyxa produces a large amount of polysaccharide possessing high activity against crown rot disease caused by Aspergillus niger in plants[29,33,36].

\section{Solubilization of insoluble zinc by the isolates}

Three media were selected to study the solubilization zinc oxide (BTG, Minimal salt medium and Pikovskaya medium) from these media Pikovs kaya medium was selected for further studies. Zinc phosphate-supplemented medium, where bacterial cells belonging to this strain are small Gram-negative rods, are able to grow in a simple mineral-glucose medium, with colonies being UV fluorescent. However, Appanna and Whitmore found that the production of protein-rich, zinc-binding moieties by $P$. fluorescens ATCC 15325 accounted for a mechanism of zinc tolerance in this strain. Although a similar mechanism may also occur in our strain during the phase of increase in free $\mathrm{Zn}$, alternatively, the protein overproduction may be a factor involved in the solubilization process and/or observed $\mathrm{Zn}$ toxicit [1,19].The absence of detectable chelated zinc suggested that the solubilization process is an indirect consequence of an increase in hydrogen ion activity in the solution [19]. The observed acidification of the medium, both in the zinc supplemented and in the control cultures, initially occurred without correlation with the release of organic acids. A cause of such an increase in the proton concentration may be the depletion of ammonia, required for protein synthesis. Only when zinc phosphate was present was there a secondary production of gluconic acid (and/or keto-derivatives) which caused a further decrease in $\mathrm{pH}$, accounting for the observed high levels of $\mathrm{Zn}$ [19].

\section{Zinc solubilization in PVK (Pikovskaya's medium)}

Zinc solubilization was studied in Pikovskaya's agar and liquid medium, a zone of inhibitions was obtained. Maximum zinc solubilization zone was observed in isolate MSS-ZF3 and MSS-ZF1 ( $90 \mathrm{~mm}$ ), followed by MSS-ZF2 (80 mm), MSS-ZB1 (56 $\mathrm{mm}$ ) MSS-ZB2 (47mm) MSS-ZB4 (45 mm) and MSS-ZB3 (44 mm) after incubation of 14 days at $37^{\circ} \mathrm{C}$ for Bacteria and at $28^{\circ} \mathrm{C}$ fungi (Figure1, 2).
The ability to dissolve appreciable amounts of zinc phosphate is not a common feature amongst the culturable bacteria of the surface soil samples. In contrast, many fungal isolates were able to produce visible clear haloes on the zinc phosphate-amended solid medium, but in only one case was the solubilization a result of bacterial activity. However, it is difficult, and not within the scope to extrapolate what the significance of this process is in the soil as it is widely recognized that only a small number of the members of bacterial soil communities are culturable with traditional isolation methods.

Optimization of Media and Growth Condition for Zinc Solubilization: Zinc solubilizing ability of bacterial strains was tested in four different types of agar media. The media selected were PVK, AYG, NBRIY and NBRiP, the maximum zone of solubilization was observed in PVK Medium, Followed by NBRIY, NBRiP, and AYG (Figure 3). From these observations as PVK medium was giving the optimum results among all four media, so PVK medium was selected for the further studies [21].

Effect of various Zinc source on efficiency of Zinc Solubilization: Various Zinc sources like Zinc Carbonate, Zinc Sulphate and Zinc Oxide, were studied in PVK Broth. The maximum zinc solubilization zone was observed in isolate MSSZF1 (90 mm), followed by MSS-ZF3 (89 mm), MSS-ZF2 (79 mm), MSS-ZB1 (57 mm) MSS-ZB2 (45 mm) MSS-ZB3 (45 mm) and MSSZB4 ( $44 \mathrm{~mm}$ ) after incubation of 14 days at $37^{\circ} \mathrm{C}$ for Bacteria and at $28^{\circ} \mathrm{C}$ fungi.

Zinc solubilizing potential varied with each isolate, the ZSB-O-1 (Bacillus sp.) obtained from the zinc ore exhibited the highest potential in Sphalerite ( $\mathrm{ZnS})$ containing medium, producing a clearing zone of $2.80 \mathrm{~cm}$. Its performance in zinc
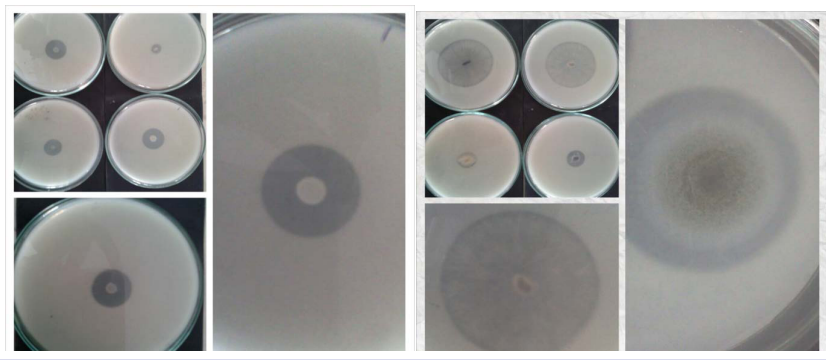

Figure 2: Zinc solubilization by the selected microbes.

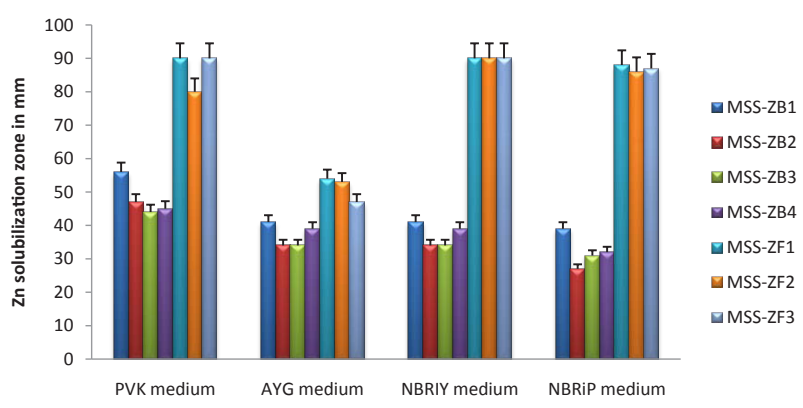

Figure 3: Effect of different medium on Zinc solubilization 
carbonate and zinc oxide was $1.50 \mathrm{~cm}$ of clearing zone with zinc oxide, respectively. The ZSB-S-2 (Pseudomonas sp.) produced maximum clearing zone of $3.30 \mathrm{~cm}$ with zinc oxide and performed poorly in zinc carbonate, with a clearing zone of $2.00 \mathrm{~cm}$. The ZSB-S-4 (Pseudomonas sp.) showed the highest potential in zinc carbonate, with a clearing zone of $4.00 \mathrm{~cm}$ [36].

Effect of different concentration of Zinc Oxide on efficiency of zinc Solubilization: Different concentration of Zinc Oxide was added in the PVK agar medium, $0.1 \%, 0.2 \%, 0.3 \%, 0.4 \%$ and $0.5 \%$. The maximum zinc solubilization zone was observed at concentration $0.1 \%$ of ZnO, MSS-ZF1 ( $90 \mathrm{~mm}$ ), followed by MSSZF3 (89 mm), MSS-ZF2 (79 mm), MSS-ZB1 (57mm) MSS-ZB2 (45 $\mathrm{mm}$ ) MSS-ZB3 (45 $\mathrm{mm}$ ) and MSS-ZB4 (44 $\mathrm{mm}$ ) after incubation of 14 days at $37^{\circ} \mathrm{C}$ for Bacteria and at $28^{\circ} \mathrm{C}$ fungi.

$0.2 \%$ of concentration shows, the maximum zinc solubilization zone was observed at concentration $0.1 \%$ of ZnO, MSS-ZF3 (55 $\mathrm{mm})$, MSS-ZF2 (52 mm), MSS-ZF1 (39 mm), MSS-ZB4 (39 mm) MSS-ZB1 (37 mm) MSS-ZB2 (34 mm) and MSS-ZB3 (34 mm) after incubation of 14 days at $37^{\circ} \mathrm{C}$ for Bacteria and at $28^{\circ} \mathrm{C}$ fungi. No zone of solubilization was observed in concentration $0.3 \%, 0.4 \%$ and $0.5 \%$. from the result, it is observed that the concentration above $0.2 \% \mathrm{ZnO}$ seems to be inhibitory for the isolates so no zone of inhibition was observed (Figure 4).

The results have been obtained by Saravanam et al. that Even at $25 \mathrm{mg} / \mathrm{kg}$ concentration, there was reduction in population within 24 hours and afterwards population remained stable up to 8 days. At zinc concentration above $100 \mathrm{mg} / \mathrm{kg}$, a further reduction in population was observed, which was more pronounced at 200 $\mathrm{mg} / \mathrm{kg}$. The results showed the inherent capacity of the isolates to tolerate various levels of zinc. At $500 \mathrm{mg} / \mathrm{kg}$ level, ZSB-S-2 was completely inhibited at the 8th day, while ZSB-0-1 recorded $2 \mathrm{x}$ $10^{4}$ cells ml-1 at the $8^{\text {th }}$ day after inoculation compared to $180 \mathrm{x}$ $10^{6}$ cells ml-1 observed just after inoculation [36].

Effect of various Carbon sources on efficiency of Zinc Solubilization: Various carbon sources like dextrose, glucose, sucrose, lactose, glycerol and xylose, were studied in PVK agar plate. The maximum zinc solubilization zone was observed in dextrose, followed by glucose, fructose, sucrose, lactose and glycerol.

In 1\% Dextrose, Maximum zone of solubilization was observed in isolate MSS-ZF2 (57mm), followed by MSS-ZF1 (56mm), MSSZF3 (54 mm), MSS-ZB1(54 mm), MSS-ZB4 (49 mm), MSS-ZB3 (49 $\mathrm{mm}$ ) and MSS-ZB2 (46 mm), after incubation of 14 days at $37^{\circ} \mathrm{C}$ for Bacteria and at $28^{\circ} \mathrm{C}$ fungi (Figure 5).

In $1 \%$ Glucose, Maximum zone of zinc solubilization was observed in isolates MSS-ZF3 ( $54 \mathrm{~mm}$ ), followed by MSS-ZF1 (49 $\mathrm{mm}), \operatorname{MSS}-Z F 2$ (47 mm), MSS-ZB4 (42 mm) MSS-ZB3 (36 mm) MSS-ZB1 (34 mm) and MSS-ZB2 (34 mm) after incubation of 14 days at $37^{\circ} \mathrm{C}$ for Bacteria and at $28^{\circ} \mathrm{C}$ fungi (Figure 5).

In $1 \%$ Sucrose zone of zinc solubilization was observed only in two isolates MSS-ZB2 $(21 \mathrm{~mm})$ and MSS-ZB2 $(20 \mathrm{~mm})$ after incubation of 14 days at $37^{\circ} \mathrm{C}$ for Bacteria and at $28^{\circ} \mathrm{C}$ fungi (Figure 5).
In $1 \%$ Lactose, Maximum zone of zinc solubilization was observed in isolate MSS-ZF1 (65 mm), MSS-ZF2 (45 mm), MSSZB4 (21 mm), MSS-ZB1 (19 mm) MSS-ZF3 (18 mm) MSS-ZB2 (18 $\mathrm{mm})$ and MSS-ZB4 $(12 \mathrm{~mm})$ after incubation of 14 days at $37^{\circ} \mathrm{C}$ for Bacteria and at $28^{\circ} \mathrm{C}$ fungi (Figure 5).

In $1 \%$ Glycerol, Maximum zone of zinc solubilization was observed in isolate MSS-ZF1 (38 mm), MSS-ZF3 (29 mm), MSSZB4 (21 mm), MSS-ZB1 (19 mm), MSS-ZF2 (17 mm) and no zone of zinc solubilization was observed in MSS-ZB2 and MSS-ZB3, after incubation of 14 days at $37^{\circ} \mathrm{C}$ for Bacteria and at $28^{\circ} \mathrm{C}$ fungi (Figure 5).

In 1\% Xylose, Maximum zone of solubilization was observed in isolate MSS-ZF3 (55 mm), MSS-ZF2 (20 mm), MSS-ZB1 (10 $\mathrm{mm})$, MSS-ZB3 $\left(9 \mathrm{~mm}\right.$ ) after incubation of 14 days at $37^{\circ} \mathrm{C}$ for Bacteria and at $28^{\circ} \mathrm{C}$ fungi, and no zone of zinc solubilization was observed in other isolates (Figure 5) [37].

The effect of different carbon sources on zinc phosphate dissolution by Pseudomonas fluorescens showed that the Glucose was found to be the only suitable carbon source for the occurrence of a clear halo around colonies on solid zinc phosphate-containing medium some solubilization was also observed with mannose [19].

Effect of various Nitrogen sources on efficiency of Zinc solubilization: Various Nitrogen sources like $\left(\mathrm{NH}_{4}\right)_{2} \mathrm{SO}_{4}$, Urea, Casein, and NaNO3 were studied in PVK Broth. Amongst all the nitrogen source zone of zinc solubilization was observed in $\left(\mathrm{NH}_{4}\right)_{2} \mathrm{SO}_{4}$ and no zone of solubilization was observed in other nitrogen source [37].

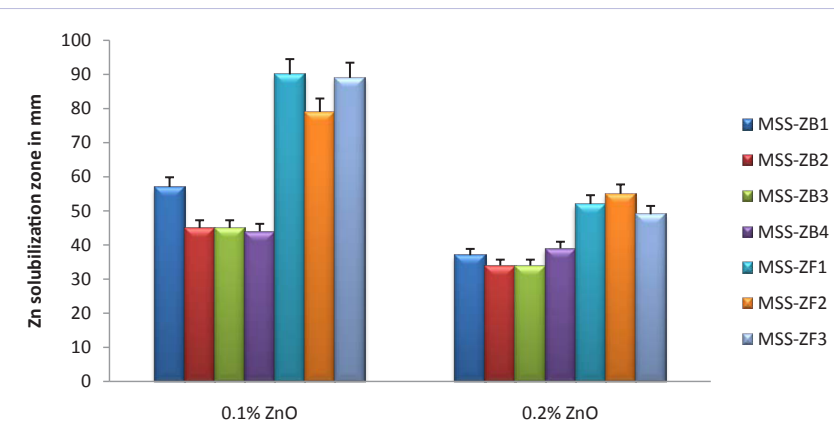

Figure 4: Effect of different ZnO Concentration on Zinc solubilization.

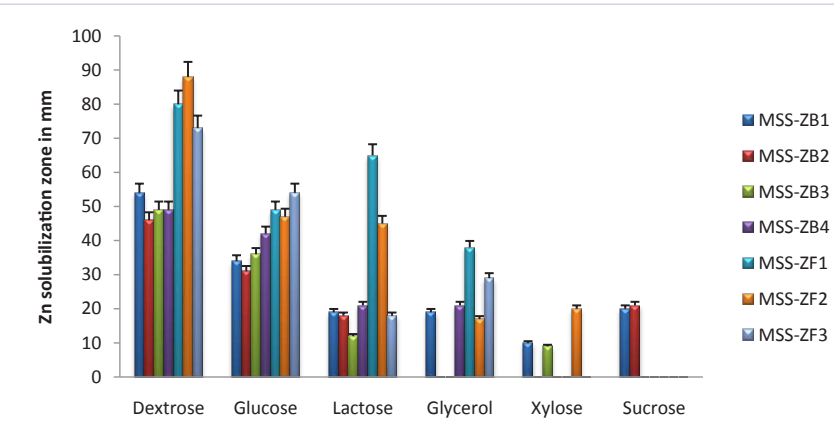

Figure 5: Effect of different carbon source on Zinc solubilization. 
Effect of temperature on efficiency of Zinc solubilization: Media composition to which the bacteria responded best was used as substrate. Inoculation was carried out by using pure colony of a bacterial grown on Basal medium of isolates and allowed to grow and maintained at $8{ }^{\circ} \mathrm{C}, 15^{\circ} \mathrm{C}, 28^{\circ} \mathrm{C}$, Room Temperature, $37^{\circ} \mathrm{C}$, and $55^{\circ} \mathrm{C}$ for 14 days respectively [20]. The Zone of Solublization was Observed and measured in millimeter (Figure 6).

Effect of pH on efficiency of Zinc Solubilization: Optimal media and temperature was used, but the $\mathrm{pH}$ of the media was set at $\mathrm{pH} 4, \mathrm{pH} 6, \mathrm{pH} 6.5, \mathrm{pH} 7, \mathrm{pH} 9$ using $\mathrm{NaOH}$ or $\mathrm{HCl}$ and grown for 14 days respectively [19]. The zone of solubilization was Observed and measured in millimeter (Figure 7).

Effect of different Salinity on efficiency of Zinc Solubilization: Optimal media and Conditions were used, but the saline concentration was added as $\mathrm{NaCl}(0.2 \%, 0.4 \%, 0.6 \%, 0.8 \%$ and $1 \%)$ and $\mathrm{KCl}(0.02 \%, 0.04 \%, 0.06 \%, 0.08 \%$ and $0.1 \%)$ in the media was set and grown for 14 days respectively (Figure 6,7) [20]. The Zone of solubilization was Observed and measured in millimeter (Figure 8,9).

Based on the optimization of media and growth condition results it was found that both bacterial and fungal cultures were able to grow and solubilize zinc optimum on carbon source $1 \%$ dextrose, nitrogen source Ammonium Sulphate and with $\mathrm{ZnO}$ $(0.1 \% \mathrm{ZnO})$. The temperature of incubation was different; $37^{\circ} \mathrm{C}$ was found optimum for bacteria and $30 \pm 2$ for fungi. From the $\mathrm{pH}$ study, it was observed that $7 \mathrm{pH}$ was optimum for bacteria and 6.5 was optimum for fungi. Further Zinc estimation was performed

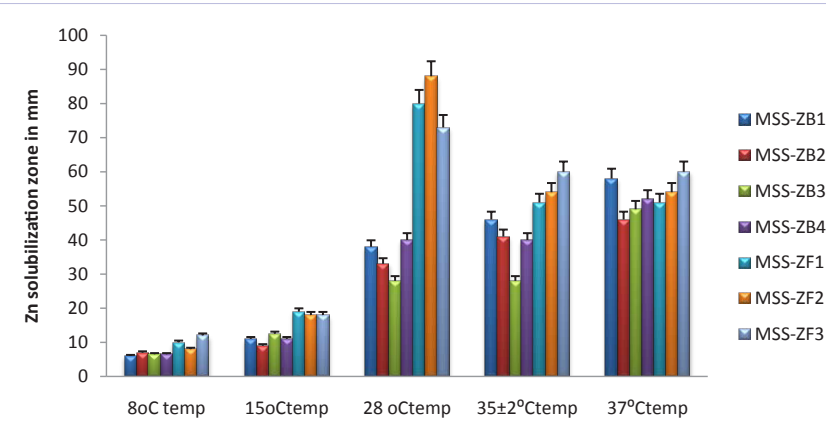

Figure 6: Effect of different temperature on Zinc solubilization.

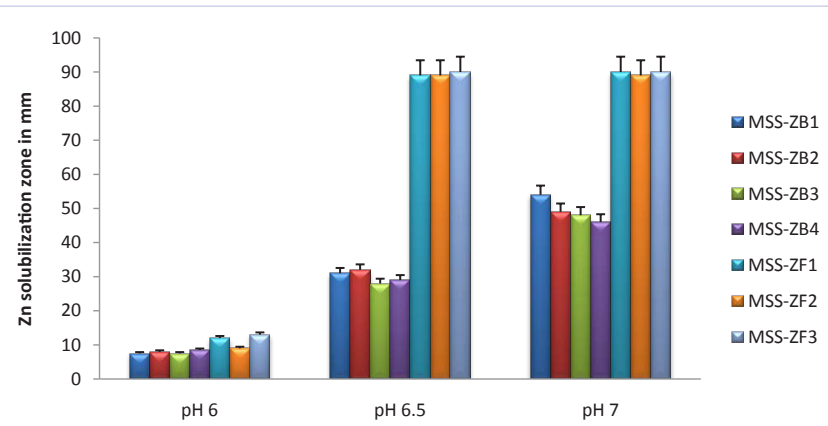

Figure 7: Effect of different $\mathrm{pH}$ on Zinc solubilization.

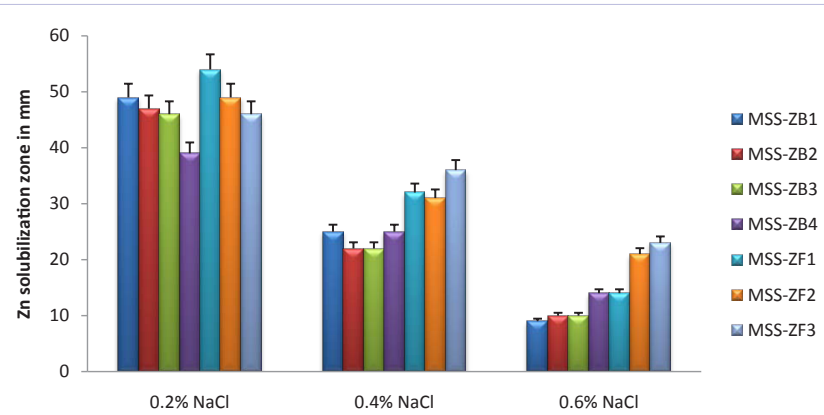

Figure 8: Effect of different $\mathrm{NaCl}$ concentration on Zinc solubilization.

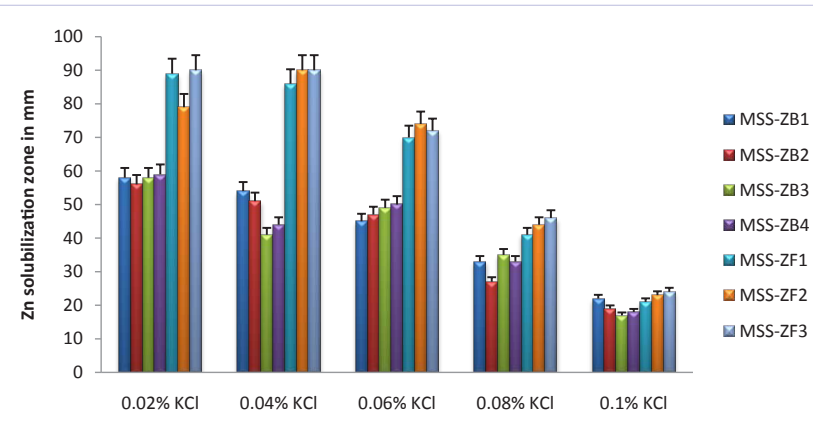

Figure 9: Effect of different $\mathrm{KCl}$ concentration on Zinc solubilization.

in the optimized media and growth condition in Pikovskaya's liquid broth amended with $0.1 \% \mathrm{ZnO}$.

The observations recorded during the growth of liquid cultures of P. fluorescens 3a by Di Simine et al are reported. Although the solid and liquid media contained different nitrogen sources, the microorganism was able to dissolve zinc phosphate in liquid medium, consistent with the observations on solid medium. Analysis of the supernatants, performed by AAS and voltammetry, showed an increase in the concentration of soluble $\mathrm{Zn}$ up to values of about $7 \mathrm{mM}$ [19]. Such an increase occurred without a meaningful difference between the free $\mathrm{Zn}$ and the total zinc concentrations, suggesting the absence of complexation phenomena involving the $\mathrm{Zn}$ in solution [19].

Di Simine et al also reported that during the time course of the experiment, bacterial proliferation occurred concurrently with a drop in the $\mathrm{pH}$ of both the control and the zinc phosphatesupplemented cultures, growth of the cultures was complete within $24 \mathrm{~h}$, the $\mathrm{pH}$ at this time reaching a value of about 4.5 [19]. The pH subsequently remained constant in the control culture, whereas a further slow decrease to values closer to $\mathrm{pH} 4$ was observed in the zinc phosphate-supplemented culture [18]. Same decrease in the $\mathrm{pH}$ was also observed in cultures which showed a shift in $\mathrm{pH}$ after growth in the broth. After 15 days, the $\mathrm{pH}$ of the broth was acidic in all cultures. The $\mathrm{pH}$ shifted from 7-7.3 to 4.8-6.5. The ZSB-S-4 culture showed the lowest $\mathrm{pH}$ value (4.8) on 15th day after inoculation, indicating a higher acidity due to growth [37]. 


\section{Conclusion}

In the present investigation, the application of PGPR had been studied for the Zinc solubilizing ability. The ability to dissolve appreciable amounts of zinc oxide was not a common feature amongst the cultivable bacteria of the surface soil samples examined in the present investigation. In contrast, three fungal isolates and four bacterial isolates were able to produce visible clear haloes on the zinc oxide amended solid medium. Amongst all the seven isolates (MSS-ZB1, MSS-ZB2, MSS-ZB3, MSS-ZB4, MSS-ZF1, MSS-ZF2 and MSS-ZF3) MSS-ZB4 and MSS-ZF3 were showing best suitable PGPR characteristics for the plant growth promotion. Considering the plant growth promoting abilities and zinc solubilizing abilities of strains, biofertilizer preparation is possible. Thus, our strains MSS-ZB4 and MSS-ZF3 can be further use as Plant growth promoting rhizobacteria for improvement of micronutrient deficiency will be promising due to its ecological, economic and ecofriendly nature.

\section{Acknowledgement}

We are thankful to UGC-Maulana Azad National Fellowship for their financial assistance.

\section{Reference}

1. Glick BR. The enhancement of plant growth by free-living bacteria Can J Microbiol, 1995;41(2):109-117.

2. Mayak S, Tirosh T, Glick B R. Effect of wild-type and mutant plant growth-promoting rhizobacteria on the rooting of mung bean cuttings. J plant growth regul. 1999;18(2): 49-53.

3. Broadley MR, White PJ, Hammond JP, Zelko I, Lux A. Zinc in plants. New Phytol. 2007;173(4):677-702.

4. Hambidge KM, Krebs NF. Zinc deficiency: a special challenge. J Nutr. 2007;137(4): 1101-1105.

5. Hirschi K. Nutritional improvements in plants: time to bite on biofortified foods. Trends Plant Sci. 2008;13(9):459-463. doi: 10.1016/j.tplants.2008.05.009

6. Cakmak I. Enrichment of cereal grains with zinc: agronomic or genetic biofortification? Plant and soil.2008;302(1):1-17. doi: 10.1007/ s11104-007-9466-3

7. Pfeiffer WH, McClafferty B. HarvestPlus: breeding crops for better nutrition. Crop Science.47:88 doi:10.2135/cropsci2007.09.0020IPBS

8. Pahlavan Rad M R., \&Pessarakli M. Response of wheat plants to zinc, iron, and manganese applications and uptake and concentration of zinc, iron, and manganese in wheat grains. Commun Soil Sci Plant Anal. 2009; 40(7-8):1322-1332. doi: 10.1080/00103620902761262

9. Wani P A, Khan M S, Zaidi A. Effect of metal-tolerant plant growthpromoting Rhizobium on the performance of pea grown in metalamended soil. Arch Environ Contam Toxicol. 2008;55(1):33-42.

10. Hafeez F Y, Naeem F I, Naeem R, Zaidi A H, \& Malik K A. Symbiotic effectiveness and bacteriocin production by Rhizobium leguminosarum bv. viciae isolated from agriculture soils in Faisalabad. Environmental and experimental botany. 2005;54(2):142-147.

11. Abaid Ullah M, Hassan MN, Jamil M, Brader G, Shah MKN, Sessitsch A,et.al. Plant growth promoting rhizobacteria: an alternate way to improve yield and quality of wheat( Triticum aestivum). Int. J. Agric. Biol.2015; 17:51-60.
12. Saharan B S, Nehra V. Plant growth promoting rhizobacteria: a critical review. Life Sci Med Res. 2011;21(1):30.

13.Gaur, A. C. (1990). Phosphate solubilizing micro-organisms as biofertilizer. Omega scientific publishers.

14. Schwyn B, Neilands JB. Universal chemical assay for the detection and determination of siderophores. Anal Biochem.19871;60(1): 47-56.

15. Sarwar M, Kremer R J. Determination of bacterially derived auxins using a microplate method. Letters in applied microbiology.1995;20(5):282-285. doi: 10.1111/j.1472-765X.1995. tb00446.x

16. Cappucino JC, Sherman N. (1992). Nitrogen cycle. Microbiology: a laboratory manual, 4th edn. Benjamin/Cumming, New York, 311-312.

17. Askeland R A, Morrison S M. cyanide production by Pseudomonas fluorescens and Pseudomonas aeruginosa. Appl Environ Microbiol.1983;45(6):1802-1807.

18. Mody B, Bindra M, Modi, V. Extracellular polysaccharides of cowpea rhizobia: compositional and functional studies. Arch Microbiol.1989;153(1):38-42. doi: 10.1007/BF00277538

19. Di Simine CD, Sayer JA, Gadd GM. Solubilization of zinc phosphate by a strain of Pseudomonas fluorescens isolated from a forest soil. Biol Fertil Soils. 1998;28(1):87-94.

20. Fasim F, Ahmed N, Parsons R, Gadd GM. Solubilization of zinc salts by a bacterium isolated from the air environment of a tannery. FEMS microbiology letters. 2002;213(1):1-6.

21. Bapiri A, Asgharzadeh A, Mujallali H, Khavazi K, Pazira E. Evaluation of Zinc solubilization potential by different strains of Fluorescent Pseudomonads. Journal of Applied Sciences and Environmental Management. 2012: 16(3):295-298.

22. Amanul HN. Substrate utilization profiles and functional diversity of microbial fractions in organic farming soil of Tharad. 2015.

23. Gyaneshwar P, Kumar G N, Parekh, LJ, Poole PS. Role of soil microorganisms in improving P nutrition of plants. In Food Security in Nutrient-Stressed Environments: Exploiting Plants' Genetic Capabilities. 2002 133-143.

24.Zimmer W, Roeben K, Bothe H. An alternative explanation for plant growth promotion by bacteria of the genus Azospirillum. Planta.1988;176(3):333-342. doi: 10.1007/BF00395413

25. Bhattacharyya R N, Pati BR. Growth behaviour and indole acetic acid (IAA) production by a Rhizobium isolated from root nodules of Alysicarpus vaginalis DC. Acta Microbiol Immunol Hung. 2000;47(1):41-51.

26. Torres-Rubio MG, Valencia-Plata SA, Bernal-Castillo J, Martínez-Nieto P. Isolation of Enterobacteria, Azotobacter sp. and Pseudomonas sp., producers of indole-3-acetic acid and siderophores, from Colombian rice rhizosphere. Rev Latinoam Microbiol. 2000;42(4):171-176.

27.Christiansen-Weniger C, Van Veen JA. NH4+-excreting Azospirillum brasilense mutants enhance the nitrogen supply of a wheat Host. Appl Environ Microbiol. 1991;57(10):3006-3012.

28. Alami Y, Achouak W, Marol C, Heulin T. Rhizosphere soil aggregation and plant growth promotion of sunflowers by an exopolysaccharideproducing Rhizobiumsp. Strain isolated from sunflower roots. Appl Environ Microbiol. 2000;66(8):3393-3398. doi: 10.1128/ AEM.66.8.3393-3398.2000

29. Cattelan AJ, Hartel PG, Fuhrmann JJ. Screening for plant growthpromoting rhizobacteria to promote early soybean growth. Soil 
Science Society of America Journal. 1999;63(6):1670-1680. doi:10.2136/sssaj1999.6361670x

30. Chandra S, Choure K, Dubey RC, Maheshwari DK. Rhizosphere competent Mesorhizobiumloti MP6 induces root hair curling, inhibits Sclerotinia sclerotiorum and enhances growth of Indian mustard (Brassica campestris). Braz J Microbiol. 2007;38(1):124-130 doi:10.1590/S1517-83822007000100026

31. Diby P. Chapter 2.In: Phisiological, biochemical and moleculer studies on the root rot (caused by Phytophthora capsici) suppression in black pepper (Piper nigrum L.) by rhizosphere bacteria. Disertasi. University Calicut. India. 2004.

32. Haggag WM, Mohamed HAA. Biotechnological aspects of microorganisms used in plant biological control. American-Eurasian Journal of Sustainable Agriculture. 2007;1(1):7-12.

33. Kumar A, Sharma S. An evaluation of multipurpose oil seed crop for industrial uses (Jatropha curcas L.): a review. Ind Crops Prod. 2008;28(1):1-10. doi:10.1016/j.indcrop.2008.01.001
34. Joseph B, Ranjan Patra R, Lawrence R. Characterization of plant growth promoting rhizobacteria associated with chickpea (Cicer arietinum L.). International Journal of Plant Production.2007;1(2):141-152. doi: 10.22069/ijpp.2012.532

35. Saravanan V S, Subramoniam S R, Raj SA. Assessing in vitro solubilization potential of different zinc solubilizing bacterial (zsb) isolates. Braz J Microbiol.2004;35(1-2):121-125. doi: 10.1590/S151783822004000100020

36. Sagervanshi A, Kumari P, Nagee A, Kumar A. Media optimization for inorganic phosphate solubilizing bacteria isolated from Anand agriculture soil. IJLPR.2012;2(3):245-255.

37. Kloepper JW, Leong J, Teintze M, Schroth MN. Enhanced plant growth by siderophores produced by plant growth-promoting rhizobacteria. Nature.1980;286: 885-886.

38. Mody B, Bindra M, Modi, V. Extracellular polysaccharides of cowpea rhizobia: compositional and functional studies. Arch Microbiol.1989;153(1):38-42. doi: 10.1007/BF00277538 